\title{
ARISTOCRACIA Y MONARQUÍA EN LOS REINOS DE CASTILLA Y LEÓN: EL CASO DE LA FAMILIA LARA
}

por

\author{
SIMON DOUBLEDAY \\ Hofstra University (New York)
}

RESUMEN: Entre los siglos XII y XIV se produjo un cambio fundamental en las relaciones de poder entre la aristocracia y la monarquía. Se analiza el caso particular de la familia Lara. Al comienzo de este período su poder derivaba ante todo de su acceso directo al monarca y su control sobre el mismo. A lo largo del siglo XII la riqueza de la familia se basaba principalmente en su posesión de tenencias, fruto más importante de la influencia en la corte. Sin embargo, desde mediados del siglo XIII, los efectos económicos del éxito castellano en la Reconquista, y especialmente la expansión de la administración real, provocaron que la vieja simbiosis entre la aristocracia y el rey fuera suplantada por un clima político de confrontación, caracterizado por la aceleración de la acumulación territorial por parte de los distintos linajes. La nueva estructura de poder aristocrático sobreviviría a la misma familia Lara, permaneciendo aún hasta la Edad Moderna, y encontrando formas de expresión en una cultura en la que, más que en cualquier otro país de Europa occidental, la autoridad y los valores de la nobleza fueron preponderantes.

Palabras Clave: Aristocracia. Nobleza. Familia. Lara. Monarquía. Tenencias.

ABSTRACT: Between the twelfth century and the fourteenth, there was a fundamental change in the basis of the Lara family's power. At the outset, their influence derived primarily from personal access to, and control over, the monarch; throughout the twelfth century, the family's wealth rested beavily on possession of the royal offices known as tenencias, which were the principal fruit of courtly influence. But from the middle of the thirteenth century, the aftershocks of the reconquests of Seville and Córdoba, and the expansion of royal administration, meant that symbiosis was increasingly supplanted by a confrontational political climate marked by an acceleration of patrimonial accumulation by aristocratic lineages such as the Laras. The new structure of 
aristocratic power would long outlast the Lara family itself, surviving well into the modern age and finding expression in a culture in which, more than in any other western European society, the authority and values of nobility were dominant.

KEY WORDS: Aristocracy. Nobility. Family. Lara. Monarchy. Tenancies.

En la historia de la aristocracia medieval de Castilla perdura un problema sumamente difícil de resolver: ¿Cuál es el origen del poder económico y territorial de la aristocracia? ¿Proviene éste de su influencia política y administrativa, o por el contrario el fenómeno se produce a la inversa? En su excelente estudio sobre el tema Simon Barton observa correctamente que, a largo plazo, la autoridad de la aristocracia quedó vinculada inextricablemente a su riqueza territorial $^{1}$. Pero vinculada ien qué sentido?. ¿Correspondía la distribución de sus tenencias simplemente a la distribución de poder territorial preexistente? ¿o, por el contrario, deberíamos atribuir un papel más decisivo a la monarquía en las dinámicas del poder? Puesto que la escasez de fuentes documentales disponibles hace imposible la tarea de reconstruir la totalidad de las tierras y propiedades de cualquier individuo o familia, sobre todo con anterioridad al siglo XII, toda respuesta a la cuestión será puramente tentativa. No obstante, el presente ensayo ofrecerá unos planteamientos preliminares, partiendo del caso específico de la familia castellano-leonesa de los Lara, de probada preeminencia entre los siglos XI y XIV ${ }^{2}$. El intento de este estudio es el de trazar, de una manera breve y episódica, un modelo de cambio socio-político a lo largo de estos trescientos años. No se pretende un análisis exhaustivo - tampoco se examinan numerosos individuos de clara importancia- sino que se intenta una aproximación muy general a la experiencia de esta familia y su relación con la monarquía. En otro estudio más amplio analizo los detalles de su desarrollo3 ${ }^{3}$

Indudablemente, en el siglo XI, la presencia patrimonial de algunos nobles - Suero Vermúdez, por ejemplo, y la familia Froilaz - ya era muy apreciable ${ }^{4}$. Para la corona, fue lógico adaptarse a dinámicas locales, y las capacidades de la monarquía no eran siempre suficientes para desatender a otros intereses 5 . Pero las monarquías de Castilla y León gozaron, en el siglo XI, de un poder excepcional. El rey fue una figura de amplios poderes, tal y como nos demuestran los

\footnotetext{
1 BARTON: Simon The Aristocracy in Twelfth-Century León and Castile, Cambridge, 1997, p. 86.

2 Agradezco a diversos investigadores del C.S.I.C. sus amplios comentarios y sugerencias a una versión temprana de este trabajo. Merecen mención especial los historiadores que forman parte del proyecto de investigación titulado «El señorío del rey (de la Castilla condal a la baja Edad Media)", dirigido por Carlos Estepa, Reyna Pastor e Isabel Alfonso.

3 Doubleday, Simon: The Lara Family: Crown and Nobility in Medieval Spain, Cambridge, Mass., 2001.

4 BARTON: Aristocracy, pp. 69-73.

5 Martínez SopenA, Pascual: «Parentesco y poder» en León durante el siglo XI. La «casata» de Alfonso Díaz», Historia Medieval, V (1987), pp. 36-40.
} 
sucesos del Poema de Mio Cid. En su reciente estudio sobre la nobleza medieval española, Marie-Claude Gerbet describe al rey como la fuente de toda riqueza, todo ascenso y toda decadencia ${ }^{6}$. La autoridad real no ha llegado a desintegrarse nunca, frente a la manera dramática en que le ocurrió a la monarquía francesa en torno al año mil. No existió nunca ni derrumbamiento total del orden público, ni un nuevo mundo de violencia y explotación?. Tampoco se dio una situación en la que el rey tenía que someterse ante los intereses privados de la nobleza. Como señala Barton, los nobles que, por cualquier razón, caían en la desgracia real se encontraban ante la posibilidad humillante de perder las tenencias que poseían, y a menudo su patrimonio privado, antes de ser exiliados, de tal modo que, exiliados o no, las consecuencias podían ser devastadoras ${ }^{8}$. Existe una tendencia generalizada que se puede acuñar como característica de la monarquía castellana: se trata de sus intentos reiterados de crear un nuevo cuerpo de grandes, cada vez más vinculados a la corona. Como Richard Fletcher ha indicado, estos intentos empezaron con los poderosos del siglo IX y siguieron hasta los privados favorecidos de los Habsburgo durante el siglo $\mathrm{XVII}^{9}$. En Galicia, ese es el procedimiento que Alfonso VI llevó a cabo con la familia Traba, hasta el punto de que casi llegaron a tener un monopolio en los puestos de la administración de la región. El ejemplo más sobresaliente es el del conde Raimundo de Borgoña, quien recibió la macro-tenencia de Galicia en el año 1079, poco después de llegar a la corte, y la retuvo durante un período de veinte años ${ }^{10}$. El mismo proceso estaba ocurriendo, al mismo tiempo y casi bajo idénticas circunstancias, en el reino embrionario de Portugal donde las exigencias militares de las campañas contra los Almorávides ofrecieron nuevas oportunidades para la nobleza de la corte de Alfonso Enríquez. Éste, por necesidad, otorgó un papel especial a miembros de familias de rango secundario ${ }^{11}$.

La ascendencia de Gonzalo Núñez (m. 1106) - primer señor de los Lara del que tenemos testimonios escritos - es todavía incierta, pero parece bastante seguro que estuvo vinculada a los Alfonso, cuyo base territorial se ubicó cerca de la frontera leonesa en la Tierra de Campos ${ }^{12}$. La hipótesis más convincente es que fue marido de Goto, hija de María Gutiérrez, hija a su vez de Gutie-

6 Gerbet, Marie-Claude: Les noblesses espagnoles au moyen age, XIe-XVe siècles, París, 1994, p. 5.

7 Véase la reseña historiográfica de BIsson, Thomas N.: «The 'Feudal Revolution'», Past and Present, 142 (1994), pp. 6-42.

8 BARTON: Aristocracy, pp. 115 y 117.

9 FLETCHER, Richard: Saint James's Catapult: The Life and Times of Diego Gelmírez of Santiago de Compostela, Oxford, 1984, pp. 16-20.

10 Pallares, María del Carmen y Portela, Ermelindo: «Aristocracia y sistema de parentesco en la Galicia de los siglos centrales de la Edad Media: el grupo de los Traba», Hispania 185 (1993), pp. 831-838; FLETCHER, St. James's Catapult, pp. 32-42.

11 MatToso, J.: Ricos-bomens, infanģoes e cavaleiros. A nobreza medieval portuguesa nos séculos XI e XII, Lisboa, 1985, pp. 245-249.

12 Martínez Sopena, Pascual: La Tierra de Campos occidental: poblamiento, poder y comunidad del siglo X al XII, Valladolid, 1985, p. 367. 
rre Alfonso ${ }^{13}$. En este caso, su suegro hubiera sido Nuño Álvarez, testigo de los diplomas reales desde el año $1038^{14}$. Lo que queda mucho menos claro es la identidad de su padre; se ha planteado la posibilidad de que fuera hijo del propio Nuño Álvarez, pero este planteamiento es problemático ${ }^{15}$. Otras posibilidades incluyen dos miembros de la familia Salvadores - y no cabe duda de que hubo vínculos estrechos entre esta familia y los Lara a lo largo del siglo XIIpero falta la evidencia necesaria para precisar la conexión paterna ${ }^{16}$. Lo que sí parece seguro es que, comparado con el resto de la nobleza, Gonzalo Núñez no fue un hombre de riqueza extraordinaria. Las evidencias nos permiten confirmar que tuvo tan sólo algunas heredades pequeñas y dispersas en Asturias, Campos y Castilla. Con su esposa poseía el monasterio de Santa María de Piasca y divisas en varias aldeas en sus alrededores, junto con otras divisas en la Tierra de Campos, Hortigüela, y los pueblos de Duruelo de la Sierra y Covale$\mathrm{da}^{17}$. Ciertamente, estas heredades no constituían en absoluto la totalidad de su señorío. Pero aún si tenemos en cuenta los peligros de especular en base a los posibles datos no documentados, parece incuestionable que su patrimonio debió ser inferior a los señoríos bien registrados de los Lara a finales del siglo XIII y a lo largo del siglo XIV. Tampoco disponemos de evidencias suficientes que nos permitan asegurar que el patrimonio de los Lara era superior al de familias rivales como los Traba o los Ansúrez cuya importancia, a pesar de su poder territorial, iba reduciéndose a principios del siglo XII.

Por lo tanto, es posible que Gonzalo Núñez fuera precisamente uno de los hombres nuevos que llegaron a ascender justo como consecuencia de una política real de renovar la élite, un hombre que había medrado gracias a la protección real. Tenemos constancia de su presencia en la corte durante el último cuarto del siglo XI. Podemos tan sólo especular sobre cuáles serían algunas de las características, o rasgos de personalidad, que le ayudaron a ganar el favor del monarca: una fidelidad sin fisuras, y quizás instintos agudos en la esfera política. Pero hay un rasgo que parece incuestionable: ser guerrero valiente y hombre de confianza en un momento de coyuntura histórica en el que esas cualidades eran más necesarias que nunca. La toma triunfal de Toledo por Alfonso VI produjo un contraataque enorme de los Almorávides y de repente se pusieron a la defensiva los reinos cristianos. El choque psicológico tuvo un gran

13 TORRes Sevilla-QuiÑONES DE LEÓN, Margarita: Linajes nobiliarios en León y Castilla (siglos IX-XIII), Salamanca, 1999, pp. 217-218.

14 Antonio Sánchez de Mora, "Aproximación al estudio de la nobleza castellana: los llamados Salvadores-Manzanedo y sus relaciones con el linaje de Lara (ss. XI-XIII)», Medievalismo (1998).

15 CARLÉ, María del Carmen: «Gran propiedad y grandes propietarios», CHE 57-58 (1973), pp. 1-224. MARTínEZ SOPENA, «Parentesco y poder», pp. 57, 73, 77-78.

16 TORRES, Linajes nobiliarios, es absolutamente persuasivo en cuanto al matrimonio de Gonzalo Núñez, pero no ofrece pruebas suficientes para su hipótesis de que éste fue hijo de Nuño Salvadores (p. 219).

17 Sabagún, 3:280-282; Arlanza, 164; La Cogolla, 287-288. 
impacto en la creación de una mentalidad de cruzada ${ }^{18}$. Para un noble como Gonzalo Núñez de Lara la situación le presentó una oportunidad de oro, pues era grande el prestigio que se podía ganar en las campañas reales. Don Gonzalo participó en una campaña en Portugal en el año 1093, y dos años después tuvo un papel destacado en otra cerca de Huesca. Los premios por esta actividad se reflejan en un documento de 1098 en el que Alfonso VI hace referencia a su «amado Gonzalo Núñez» ${ }^{19}$ quien fue recompensado, como muchos palaciegos fieles, con tenencias estimables como Carazo, Huerta y Osma ${ }^{20}$. Y más llamativa todavía fue su tenencia de Lara, que disfrutó durante catorce años por lo menos (1081-95), explotada como si fuera un patrimonio, proceso que, por otra parte, parece bastante común en la época ${ }^{21}$.

El auge de los Lara alcanzó un apogeo durante el reinado de Urraca (11091126). Tradicionalmente, este reinado se ha caracterizado como período de anarquía, desasosiego, e incluso de una «revolución feudal» ${ }^{22}$, pero en muchos aspectos la reina fue políticamente activa y eficaz, y en consecuencia la protección del rey fue fundamental ${ }^{23}$. Este es el contexto y el sine qua non de la influencia inmoderada de Pedro González de Lara, hijo de Gonzalo Núñez, con quién la reina mantuvo una relación escandalosa (por lo menos para Diego Gelmírez, arzobispo de Santiago), a partir del año $1112^{24}$. La relación subraya, de una manera especialmente literal, la intimidad de la esfera política en el siglo XII. Se puede trazar la presencia de Pedro González desde principios del reinado, cuando actúa como alférez real, pero su proximidad con la reina le permite adquirir una serie de tenencias importantes en Castilla y Campos, y mantener su control de la tenencia clave de Lara, de la que evidentemente disfrutó casi como propiedad privada ${ }^{25}$.

El éxito sin paralelo de los Lara en obtener importantes tenencias no se puede explicar por ningún predominio territorial por encima de otras familias nobles. Durante el siglo XII, establecieron su control patrimonial en solamente

18 FLETCHER, Richard: «Reconquest and Crusade in Spain, c. 1050-1150», Transactions of the Royal Historical Society, 5th ser., 37 (1987), pp. 31-47.

19 La Cogolla, p. 291.

20 Carazo y Huerta, 1083 (La Cogolla, pág. 257); Osma, 28 febrero 1094 (ibid., p. 284-285).

21 Documentación medieval del monasterio de Valvanera (siglos XI a XIII), ed. GARCíA TuRZA, Francisco Javier: Zaragoza, 1985, p. 137 (25 julio 1081); ibid., pp. 287-288; Pruebas de la historia de la Casa de Lara, ed. SALAZAR y CASTRO, Luís de: Madrid, 1694, p. 506 (1095).

22 BoNNASSIE, Pierre: «From the Rhone to Galicia»: origins and modalities of the feudal order», From Slavery to Feudalism in South-Western Europe, Cambridge, 1991, pp. 122-124.

23 Reilly, Bernard F.: The Kingdom of León-Castilla under Queen Urraca, 1109 -

1126, Princeton, 1982, pp. 46, 361-362; GrassotTI, Hilda: Las instituciones feudo-vassalláticas en León y Castilla, 2 vols., Spoleto, 1969, pp. 953-987.

24 Historia Compostellana, ed. FalQue ReY, Emma: Corpus Christianorum, Continuatio Mediaevalis, LXX, Turnholt, 1988, p. 234.

25 GaRCía Pelegrín, José: Studien zum Hochadel der Königreiche León und Kastilien im Hochmittelalter, Munster, 1991, p. 122. 
un señorío grande, el de Molina, en la frontera con Aragón, y son reveladoras tanto la manera de recibirlo como la manera en que lo han utilizado. Significativamente, parece haber sido la posición de Manrique como alférez lo que le ha permitido adquirir Molina. En el fuero que otorga a la ciudad, Manrique dice: «Me he encontrado con un lugar completamente desierto, que quiero repoblar». Uno podría sospechar que Manrique se hizo cargo de Molina, sin apenas resistencia, cuando estaba virtualmente abandonada, o despoblada, alrededor del año 1134, en su primer nombramiento como alférez y mientras las fuerzas castellanas habían avanzado hacia Zaragoza ${ }^{26}$. Es posible que Alfonso VII haya otorgado Molina al alférez como recompensa por su servicio en la campaña de Zaragoza. Su decisión en cuanto al período prolongado de posesión puede atribuirse a los efectos de la continua fricción entre Castilla y Aragón por razones fronterizas. En cuanto al destino de Molina, a la muerte de Manrique, el señorío fue dividido: su viuda recibió la mitad y la otra le fue otorgada a su hijo Pedro Manrique (d. 1202), estrategia que hubiera sido impensable un siglo más tarde, a finales del siglo XIII, cuando los Lara intentaron establecer una base territorial unificada en la frontera aragonesa ${ }^{27}$.

Las tenencias castellanas y leonesas que se otorgaban como recompensa no eran hereditarias, como hubiera sido el caso si la corona quisiera solamente complacer el poder territorial preexistente. La rapidez con que se alternaron entre diferentes miembros de la nobleza indica de nuevo la fuerza política de la monarquía. Pocas veces encontramos evidencia de una tenencia a largo plazo. La tenencia de Lara es un ejemplo; otros dos serían los de Toledo y Baeza, tenencias de Manrique Pérez de Lara (d. 1164) a mediados del siglo XII, aunque en este caso se trata de dos tenencias fronterizas. Con respecto al reino de León la situación estaba más controlada todavía. Allí, un sobrino de don Manrique, un segundo Gonzalo Núñez (d. 1225), consta que tenía un gran número de tenencias a finales del siglo. Pero a pesar de que fuera altamente favorecido por el rey sus tenencias - Lemos, Trastámara, Asturias, etc.- duraron siempre dos años o menos. Tampoco las tenencias de los Lara tuvieron una relación estricta con su base patrimonial. Entre muchos ejemplos tenemos, otra vez, el de Manrique y su hijo. Poco después del año 1160, la corona le encargó a Pedro Manrique importantes tenencias fronterizas desde Lara y San Esteban, pasando por la de Atienza y la de Transierra, hasta Cuenca. Se puede admitir que es posible que sus posesiones en Molina lo convirtieran en el candidato lógico para cumplir con este cometido. Sin embargo, aparte de Molina, sus posesiones patri-

26 El fuero de Molina de Aragón, ed. SANCHO IzQuierdo, Miguel: Madrid, 1916, pág. 63.

27 Archivo Histórico Nacional, Ordenes Militares, Calatrava, carp. 455, 15P; Real Academia de Historia B-10, 40v; SALAZAR y CASTRO, Luís de: Historia genealógica de la Casa de Lara, Madrid, 1696-97, Bilbao, 1988, p. 4:1; GonZÁLEZ, Julio: El reino de Castilla en la época de Alfonso VIII, 3 vols., Madrid, 1960, p. 1:280.

Hispania, LXI/3, núm. 209 (2001) 999-1016 
moniales en esta región eran pocas y dispersas ${ }^{28}$. Se deben atribuir sus tenencias a la influencia política de su padre Manrique, quien había preparado el camino en la corte, y para explicar esta influencia, deberíamos enfatizar sus talentos militares. La habilidad de Manrique en complacer al emperador Alfonso VII, por sus hazañas de armas y su generosidad caballeresca, había sido vital para la recuperación rápida de los Lara a mediados de siglo. Ya había disfrutado las tenencias fronterizas de Avila y Toledo mientras estaba en la corte real y sirvió como alférez de 1134 a $1137^{29}$. Estaba presente casi continuamente en la corte, de manera que le fue posible acumular más tenencias fronterizas. Medinaceli y el pequeño pueblo que entonces era Madrid le fueron asignadas en la década siguiente. Puesto que nunca volvió a adquirir el puesto de alférez, su participación en las campañas militares de esta época fue probablemente como teniente de Toledo. El Poema de Almería elogia a Manrique al describir la toma de varias ciudades andaluzas como Andújar y Baeza ${ }^{30}$. Su protagonismo en estas campañas tan celebradas aumentó su brillante prestigio en la corte y aceleró el ciclo de éxito. Mientras tanto, la acumulación de territorio patrimonial seguía siendo lento y fragmentario. El predominio de la nobleza sobre los otros habitantes de los dos reinos de Castilla y León, aunque bien destacado, no llegó a su culminación hasta desarrollarse los mayorazgos a finales del siglo XIV. Cabe pensar, por lo tanto, que el patrimonio era una base de poder bastante débil en el siglo XII. La clave para su adquisición no era otra que la influencia en la corte.

Pero desde mediados del siglo XIII, la conflictividad fue la marca predominante de la relación entre la familia Lara y la corona de Castilla. Esto debería considerarse como efecto de un programa ideológico bastante ambicioso, iniciado por la monarquía, durante una época de dislocación económica. Se había acabado, en gran parte, la vieja simbiosis. Es verdad que la relación no se trasformó en antitética de la noche para la mañana: la corona seguía buscando la cooperación de los Lara, como la de otros linajes —el rey, después de todo, fue también señor aristocrático- y los Lara por su parte seguían buscando cualquier oportunidad de aumentar su influencia en la corte. Pero a su vez, mientras la corona desarrollaba su nueva política de independencia administrativa, la familia Lara intentó acumular un patrimonio mucho más amplio que le permitiera ampliar su autonomía. El proceso de expansión territorial, a finales del siglo XIII, corresponde a una tendencia general y generalizada según la cual el patrimonio y la jurisdicción patrimonializada empezaron a considerarse esenciales como base fundamental del poder aristocrático. Si bien en el siglo

28 En esta región fronteriza, por ejemplo, Pedro Manrique vendió el pueblo de Valtablado, al sureste de Cifuentes (AHN Códices 1046B, 42-43; AHN Ordenes Militares, Santiago, carp. 98 no.1); otorgó unas salinas en Bonilla al monasterio de Sacramenia (AHN Códices 104B, 26r); y obtuvo un medio de Beteta del obispado de Sigüenza (BARTON, Aristocracy, p. 282).

29 Fue alférez entre el 10 de noviembre de 1134 ( La Cogolla, pág. 308) y el 2 de junio de 1137 (Recueil des chartes de labbaye de Silos, ed. FÉrotin, Marius: Paris, 1897, p. 72).

30 Chrónica Adefonsi Imperatoris, ed. SÁNCHEZ BELDA, Luís: Madrid, 1950, p. 183. 
XII el poder había dependido de la influencia en la corte y de las relaciones con el monarca, ahora iba a depender más que nada del control de la tierra. En realidad los dos factores fueron siempre fundamentales, lo que ocurría ahora era sencillamente un cambio de énfasis, sutil, vacilante, pero inconfundible. Un aspecto muy significativo de este cambio fue el auge de señoríos muy extensos. Según Reyna Pastor, ya a finales del siglo XIII, fue tanto el poder de los miembros más destacados de linajes nobiliarios que se podrían considerar estados dentro del estado ${ }^{31}$. Mientras tanto, en todos los rincones de los viejos reinos de Castilla y León se acentuaba el señorío jurisdiccional de la nobleza ${ }^{32}$.

Tradicionalmente se pensó que estas conquistas andaluzas acarrearon directamente consigo un aumento espectacular de las fortunas aristocráticas ${ }^{33}$. Teorías más recientes parecen concurrir en que no únicamente los grandes eran siempre los beneficiarios exclusivos de estas ganancias ${ }^{34}$. Se ha demostrado que la imposición de un régimen señorial en Andalucía no empezó antes del fin del siglo XIII y que la nobleza llegó a controlar solamente un cuarto de la tierra, proporción que se duplicaría durante los siglos XIV y XV35. La gran mayoría de los nuevos pobladores fueron peones. Ana Rodríguez ha sostenido que se produjo una correlación inversa entre el protagonismo político de la nobleza en la corte y su recompensa territorial en Andalucía ${ }^{36}$. Parece confirmar la teoría el caso de Nuño González de Lara (d. 1275), tan destacado en la corte de Alfonso X el Sabio. Sin duda alguna, disfrutaba don Nuño unas tenencias estimables. En el sur recibió Sevilla, Jerez, y Écija; y al norte, Bureba, La Rioja y Castilla la Vieja. El rey Alfonso X no podía comprender el descontento de su amigo de la infancia. Sin embargo, es fácil de explicar en vista de los nuevos cambios de percepción de la aristocracia. Nuño González había recibido pocas heredades patrimoniales y, a la vista de los territorios inmensos que se habían abierto en la frontera, ello parecía casi insultante. Recibió un sólo señorío considerable llamado Corixad Albat y una propiedad más pequeña en Aznalcázar,

31 PASTOR, Reyna: «Reflexiones sobre los comienzos de la formación política feudo-vassalítica en Castilla y León", Realidad e imagenes del poder. España a fines de la Edad Media, ed. Adeline Rucqoi, Valladolid, 1988, p. 22.

32 BeCEIRo PITA: Parentesco, Poder y Mentalidad, pp. 62-67.

33 Véase, por ejemplo, Moxó, Salvador de: «La nobleza castellana en el siglo XIV», AEM 7 (1970-71), pp. 494-496; y una versión más sútil, RuIZ, Teófilo: «Expansion et changement: la conquête de Séville et la société castillane», Annales E.S.C. 34 (1979), pp. 555-557.

34 BeCeiro PIta: Parentesco, Poder y Mentalidad, pp. 63-65.

35 COllantes De Terán SÁNCHeZ, Antonio: «Los señoríos andaluces. Análisis de su evolución territorial en la Edad Media», Historia, Instituciones, Documentos, 6 (1979), pp. 89-112; LADERO QUESADA, Miguel Ángel: «Sociedad feudal y señoríos en Andalucía», En torno al feudalismo bispánico, pp. 438-448; CABrERA, E.: «The Medieval Origins of the Great Landed Estates of the Guadalquivir Valley», Economic History Review, 2nd series, XLII, 4 (1989), pp. 469-471.

36 Rodríguez LóPEZ, Ana María: «Linajes nobiliarios y monarquía castellano-leonesa en la primera mitad del siglo XIII», Hispania 185 (1993), p. 847.

Hispania, LXI/3, núm. 209 (2001) 999-1016 
junto con unas casas en Sevilla y unos molinos en Alcalá de Guadaira ${ }^{37}$. Pero escaso consuelo podrían haberle producido unos molinos cuando otros nobles habían recibido grandes extensiones de tierra en Sevilla. Los Lara obtuvieron muy poco en Andalucía y nunca podrían llegar a establecer allí un pie firme.

A nivel aristocrático, la riqueza fue un asunto muy relativo. A juzgar por las cláusulas suntuarias en los reglamentos de precios de esta época, había cierta ansiedad entre la aristocracia con respeto al ascenso de los caballeros villa$\operatorname{nos}^{38}$. Si a ello sumamos el incremento de salarios que fue necesario para atraer a los nuevos pobladores de Andalucía, el resultado fue una inflación altísima en Castilla, lo cual amenazó con minar los ingresos de la nobleza ${ }^{39}$. Entre los años 1268 y 1294 había una inflación de mil por cien. De hecho, el rey Alfonso X intentó controlarla mediante la estabilización de precios, sueldos y comercio de exportación, pero todo resultó en vano ${ }^{40}$. Una carta escrita por Ali Ibn Yusuf (líder de los Marinides en Marruecos) en 1272, hace referencia precisamente a la desconfianza del noble: "que vos asacó monedas falsas é que vos quebrantó el fuero bueno que usábades en antiguedad, pues demudáronse vuestras estancias é encarescieron las casas é desatajaron los mercadores» ${ }^{41}$. Al encontrarse con esta crisis económica, los Lara comenzaron una nueva estrategia, la de acumular señoríos grandes en otra frontera, la de Aragón. Durante las próximas tres generaciones cada señor principal de la familia Lara intentará adquirir un patrimonio importante al este, patrimonio que en cada caso tendrá una virtual autonomía: se trata de Albarracín, Molina, y Vizcaya. Finalmente, queda decir que siempre la ambición por el patrimonio conlleva a la guerra contra la corona. Los problemas económicos que habían causado las reconquistas recientes en Andalucía intensificaron una reacción aristocrática contra las nuevas pretensiones de la monarquía castellana. Durante el reinado de Alfonso X el Sabio, la teoría política se distanció de la idea de sociedad basada en vínculos feudales y avanzó hacia un nuevo concepto de unidad, aunando a todos bajo la autoridad real ${ }^{42}$. Claro que todavía no existía el absolutismo - el rey no estaba por encima de la ley - y permanecía como fundamental la idea de obligaciones

37 GonZÁlez, Julio: Repartimiento de Sevilla, 2 vols., Madrid, 1951, pp. 1:63, 1:262, 2:307; AHN Sellos, caj. 65 no. 27.

38 GARCía RÁmILA, Ismael: «'Ordenamientos de posturas y otros capítulos' otorgados a la ciudad de Burgos por el rey Alfonso X», Hispania 19 (1945) pp. 179-235, 20 (1945) pp. 385-439, 21 (1945) pp. 605-50; Lourie, Elena: «A Society Organized For War: Medieval Spain», Past and Present, 35 (1966), pp. 72.

39 RUIZ, «Expansion et changement», pp. 552-553.

40 CARLÉ, María del Carmen: «El precio de la vida en Castilla del Rey Sabio al Emplazado», CHE, XIV (1950), pp. 139-141; TodesCA, James J.: «What Touches All: Coinage and Monetary Policy in Leon-Castile to 1230» (Tesis doctoral, Fordham University, 1996), pp. 334-363, 437-438.

41 "Crónica del rey don Alfonso décimo", Crónicas de los reyes de Castilla, ed. Rosell, Cayetano: Biblioteca de Autores Españoles LXVI, Madrid, 1875, p. 18.

42 Siete Partidas, II, 1, v; O'CALlaghan, Joseph: The Learned King: the Reign of Alfonso X of Castile, Philadelphia, 1993, pp. 17-29. 
mutuas entre el rey y su pueblo. Sin embargo, en la nueva ideología podemos ver los orígenes de la autoridad centralizada que es una de las características del estado moderno.

Tradicionalmente ha existido una fe incuestionable en el triunfo de los principios monárquicos sobre los aristocráticos, considerando los primeros como intrínsecamente positivos. Sin embargo ambos poderes, corona y nobleza, perseguían la lógica casi inevitable de una sociedad jerárquica, intentando promover sus intereses a través de la acumulación de autoridad. A pesar de que la corona tuviera la apariencia de una fuerza del orden y de la justicia, no era una institución inherentemente progresiva. De hecho, es bastante claro, por ejemplo, que las Cortes no se originaron desde una perspectiva democrática, sino por una necesidad de reforzar las bases políticas de la monarquía. La ambición de Alfonso X el Sabio por la búsqueda de la corona imperial en el siglo XIII es tan pertinaz como la de cualquier otra casa aristocrática $\mathrm{y}$, a posteriori, se puede afirmar que la nobleza medieval nunca alcanzó la capacidad destructiva de la monarquía de los Habsburgos pero, en última instancia, es esta misma monarquía la que conduciría a España hacia el estancamiento económico, la catástrofe étnica y el hambre mortal varios siglos más tarde. Fue la corona, durante el siglo XIII, la que derribó el status quo. Había un esfuerzo consciente por limitar y superar la estrecha relación entre la nobleza y la monarquía que había caracterizado el siglo anterior. Alfonso X buscó el soporte de las élites urbanas como base de compensación, otorgando exenciones de impuestos a los caballeros villanos ${ }^{43}$. Se resucitó también el tribunal real, a fin de imponer los nuevos códigos legales, y ello provocó una reacción negativa casi inmediata por parte de la nobleza, cuyo papel activo en el proceso de cambio judicial había sido muy reducido. El carácter y la composición de este tribunal fueron el centro de las quejas nobiliarias durante la rebelión que le siguió. Uno de los resentimientos fundamentales es que se estaba excluyendo cada vez más a la alta nobleza de posiciones de influencia administrativa. A lo largo de los siglos XI y XII el poder aristocrático había sido instrumento del poder monárquico y su papel en las tenencias aumentaba inmensamente la importancia de la nobleza. En los nuevos estatutos, en cambio, se desarrollaban mecanismos alternativos de administración, y la corona estaba eliminando paulatinamente su dependencia en la aristocracia. Se ha afirmado que la creación de nuevas plazas, de adelantado mayor y merino mayor representa un paso importante hacia la centralización. Pero los nobles perdieron con ello su monopolio en la administración territorial y llegaron casi a la rebelión ${ }^{44}$. A menudo las crónicas oscurecen la magnitud del descontento entre los grandes. La manera más amplia, menos

43 RuIZ, Teófilo F.: «Expansion et changement», pp. 557-558; idem, «The Transformation of the Castilian Municipalities: the case of Burgos, 1248-1350», Past and Present no. 77 (1977), pp. 6-7.

44 Jular PÉreZ AlFaro, Cristina: Los adelantados y merinos mayores de León (siglos XIII-XV), León, 1990, pp. 186-188, 539-541.

Hispania, LXI/3, núm. 209 (2001) 999-1016 
faccionaria, en que ahora se asociaban los nobles, refleja la aparición de prácticas más estrictamente políticas en este período. En el año 1271 se constituyó una alianza de rebeldes bajo la dirección de Nuño González de Lara y el infante Felipe. Además de diversos miembros de la aristocracia, según el cronista Jerónimo de Zurita, se unieron al grupo algunos procuradores urbanos ${ }^{45}$. Fue en términos políticos que expresaron sus quejas los rebeldes de $1272 \mathrm{y}$, por tanto, dichas rebeliones deben considerarse como una reacción, ante todo, al aumento de la autoridad monárquica, a pesar de que en sus bases existiera también una ansiedad económica. A veces las dos cuestiones son indisociables. Cuando los rebeldes se enfrentaron con el ejército real, cerca de Lerma, su portavoz, Nuño González de Lara, presentó las quejas. Entre ellas estaba la demanda de que los servicios deberían ser solicitados de una manera más justa; se queja, asimismo, de que tampoco fue justa la alcabala que se imponía en Burgos, y que eran perjudiciales las acciones de los merinos reales (considerados por los nobles como obstáculo para el crecimiento de sus propios señoríos) los cuales deberían ser reemplazados por adelantados, puesto tradicionalmente asociado con la aristocracia ${ }^{46}$

Cada una de estas quejas refleja una mezcla de descontento puramente económico y desconfianza especial en cuanto a las pretensiones de la corona, pero es el resentimiento con respecto a la monarquía lo que representa el denominador común. El resto de las quejas de los rebeldes se erigen en contra de las nuevas leyes reales y del uso de alcaldes no pertenecientes a la nobleza con atributos para juzgar a la nobleza en el tribunal real. Las innovaciones en el tribunal violan, fundamentalmente, el principio tradicional de ser juzgado por los iguales y ello entra en conflicto con un concepto más antiguo de equilibrio entre el poder real y el pueblo ${ }^{47}$. Aunque suene como muy armónica, la afirmación del cronista de que, durante las negociaciones entre el rey y los rebeldes en las Cortes de 1272, todos los presentes asintieron en que el rey tenía razón y que los nobles habían provocado un alboroto sin justificación, parece poco creíble. En realidad, los rebeldes estaban dando voz a una amplia gama de preocupaciones y, a corto plazo, la respuesta real fue acomodarlas, pero eran reaccionarios en el sentido más estricto de la palabra. Estaban reaccionando contra la innovación en el gobierno real. Demandaban, entre otras cosas, que las leyes, privilegios, costumbres y fueros del reino de Alfonso $\mathrm{X}$ fueran los mismos que durante el reinado de su padre y de su abuelo; que la situación con respeto a las minas de sal y hierro fuera idéntica a la disfrutada durante el reinado de su padre; que la manera de adquirir los montazgos permaneciera inmóvil con res-

45 Crónica de Alfonso X, p. 15.

46 Crónica de Alfonso X, pp. 19-20.

47 O'CaLlaghan: The Learned King, pp. 80, 214. 
pecto al reinado anterior; y que la lista de exportaciones prohibidas no variara tampoco con respecto al reinado de Fernando III ${ }^{48}$.

El estereotipo más frecuente que caracteriza a esta época es el de una monarquía racional y pacífica que paulatinamente se hizo dueña de una nobleza caracterizada como turbulenta. La turbulencia, a su vez, se ha visto a menudo como la debilidad hereditaria de una única clase en la sociedad medieval, una nobleza de egoísmo inigualado. Un punto de vista moderno desde una perspectiva liberal nos impide hablar de turbulencia en el contexto de resistencia popular, mientras que una fe en el estado centralizado hace incongruente que nos refiramos a una monarquía 'turbulenta'. Pero el sentido de un poder único, abstracto y soberano, con un monopolio de violencia legítima, fue, en términos generales, ajeno a la Edad Media. Incluso en Las Siete Partidas, texto tendente a exaltar la figura del rey, se contempla el derecho de la nobleza a sublevarse bajo ciertas condiciones. Como explicó Otto Brunner en el contexto de las tierras alemanas medievales, había una multiplicidad de poderes disfrutando el derecho y el deber de perseguir acciones políticas, aún contra los poderes superiores. Se suele admitir con facilidad la capacidad de actuar por motivos políticos cuando se trata de los poderes que aparentemente representan al estado, sin embargo, cuando se trata de los poderes locales, se juzga con ligereza que actúan por avaricia o egoísmo personal ${ }^{49}$. Pensamos, por ello, que no se puede atribuir el descontento aristocrático de Castilla a una presunta flaqueza moral. Los peligros de tal razonamiento aparecen sutilmente reflejados en un fragmento de la historia de los Lara escrita por Salazar y Castro. Ante la evidencia de una relación cada vez más deteriorada entre la corona y la familia Lara a finales del siglo XIII el cronista Salazar se equivoca al trazar la genealogía de Juan Núñez I de Lara (d. 1294) y lo inscribe en su texto como si se tratara de dos personas diferentes. A su primer Juan Núñez lo define como hombre de "compostura grande de costumbres, afabilidad generosa, valor heroico y natural sosiego», mientras que a su segundo Juan Núñez (de hecho, la misma persona) lo juzga como «violento, y repugnante» ${ }^{50}$.

Es imprescindible preguntarse cuáles eran las causas del descontento de la familia, y el contexto de su comportamiento. En el fondo, la intensificación del conflicto debe atribuirse a su búsqueda de poder patrimonial, una respuesta a su vez a la expansión de ambiciones reales a mediados del siglo XIII. Los Lara necesitaban de un nivel de poder territorial que pudiera elevarles por encima de las presiones económicas. Concretamente, mostraron una obsesión con los señoríos claves de Albarracín y Molina y con el proceso de establecer una base de poder en la frontera aragonesa. Se ha dicho, quizás correctamente, que Juan

\footnotetext{
48 Crónica de Alfonso X, pp. 30-31.

49 BRUNNER, Otto: Land and Lordship, ed. Howard Kaminsky y James Van Horn Melton, Philadelphia, 1992, pp. 3-4.

so Casa de Lara, pp. 4:117-118. La genealogía correcta se estableció en GAIBROIS DE BALLESTEROS, Mercedes: Sancho IV de Castilla, 3 vols., Madrid, 1922-28, pp. 2:83-84.
} 
Núñez intentaba crear un estado bloqueador en esta frontera ${ }^{51}$. En cualquier caso, la relación entre la familia y la corte era la de una dialéctica frenética entre una confrontación profunda y una reconciliación superficial. En el año 1290, por ejemplo, volvió Juan Núñez a la corte después de arreglar un matrimonio entre su hijo y la heredera de Molina ${ }^{52}$. Pero fue frágil cada fase de cooperación y, a su vez, cada confrontación reveló una cicatriz que disfrazó nada más que cosméticamente el magnetismo por la corte. Inversamente, durante los períodos de supuesta amistad, fueron palpables las tensiones políticas. Uno de los temas más fascinantes en las crónicas de Sancho IV y Fernando IV es la plétora de rumores de asesinatos planeados por el rey contra los Lara. En el año 1290 se había mandado una carta a un confidente de Juan Núñez diciendo que el rey Sancho IV quería su asesinato. Don Juan huyó al monasterio de San Andrés de Arroyo y sólo tras grandes esfuerzos de persuasión se decidió a regresar. Durante una etapa posterior de reconciliación, estando don Juan Núñez en Toledo, le asustó nuevamente un informe según el cual el rey iba a matarle y cuando intentó huir, durante la noche, encontró cerradas las puertas de la ciudad. Según el cronista, el rey Sancho reprendió al supuesto propagador de rumores y con ello se restauró una apariencia de paz ${ }^{53}$. Por tercera vez, en 1308, y ahora según datos del cronista de Fernando IV, ciertas personas anónimas - y aparentemente celosas - informaron a Juan Núñez II (d. 1315) que el rey tenía intención de asesinarle. El de Lara huyó a Torrelobatón, en donde se juntó con el infante Juan, quien había oído el mismo rumor ${ }^{54}$. El cronista niega la credibilidad de estos rumores, sin embargo parece perfectamente posible que algunos de ellos fueran legítimos, sino todos. Al fin y al cabo, es la misma crónica la que relata que tres años más tarde, el rey intentaría conseguir la ayuda de Juan Núñez para capturar o asesinar al infante Juan, después de que éste le decepcionara durante una campaña en Algeciras. Juan Núñez se negó en aquella ocasión a colaborar en la conspiración real, pero ello no impidió que el rey Fernando siguiera buscando una manera de matar al infante ${ }^{55}$.

Es de suma importancia para el análisis de las relaciones entre ambos poderes que no percibamos el descontento de los Lara como aislado ni como únicamente interesado. Sirve en apoyo de este juicio un fragmento de la Gran Crónica de Alfonso onceno que data de finales del siglo XIV. Esta crónica nos informa

\footnotetext{
51 Moxó, Salvador de: «De la nobleza vieja a la nobleza nueva: la transformación nobiliaria castellana en la baja edad media», $C H, 3$ (1969), pág. 40.

52 "Crónica del rey don Sancho el Bravo», Crónicas de los reyes de Castilla, ed. Rosell, Cayetano: Biblioteca de Autores Españoles LXVIII, Madrid, 1875, pág. 84; ZuRITA, Jerónimo: Anales de la Corona de Aragón, ed. Angel Canellas López, 5 vols., Zaragoza, 1967-85, IV, cap. cxx.

53 Crónica de Sancho el Bravo, pp. 83-84.

${ }_{54}$ Memorias de D. Fernando IV de Castilla, ed. Benavides, Antonio: 2 vols, Madrid, 1860, pp. 1:197-98.

ss Ibid., pp. 1:228, 231-33.
} 
que, reuniéndose las Cortes en Burgos en el verano de 1315, el viejo Juan Núñez II llegaba casi a su muerte,

E fizo su testamento, y por que non avie fijo heredero nin fija que heredase después de su muerte mandó por su alma a Lara, que era suya, e quanto en el mundo avia. E los fijos dalgo de Castilla acordaron que la casa honrrada de Lara que no era bien que quedase sin señor, por que antigua mente fue un solar de los tres de Castilla; e con otorgamiento del rrey y de los tutores y de todos los otros en general, dieron señor heredero a la casa de Lara, e este fue Don Joan Núñez [III]....E por que este Joan Núñez... heredase la casa de Lara, echaron pecho entre sí los fijos dalgo de Castilla, e ayuntaron muy grande aver, por que fueron conpradas tierra e villas e castillos para el señorío de Lara56.

Este relato presenta varios hechos desconcertantes. ¿Por qué el viejo don Juan Núñez habría enajenado sus tierras cuando, más que nunca, le eran imprescindibles para su linaje? Y todavía más curioso, ¿por qué la reacción general de los presentes en las Cortes habría sido la de intentar impedírselo? Curiosamente, este relato no aparece en la Crónica de Alfonso onceno, más temprana que la Gran crónica que acabamos de citar. En la primera se nos informa escueta y sencillamente que, estando en las Cortes, murió el señor de Lara ${ }^{57}$. Evidentemente la historia posterior puede ser ficticia. Pero aunque así lo fuera es reveladora la diferencia en su perspectiva. Mientras que para la crónica temprana los motivos de la nobleza son mercenarios y el autoritarismo real es justo, las simpatías de la Gran Crónica se inclinan resueltamente de parte de la nobleza ${ }^{58}$. Este punto de vista no es único ya que el conflicto entre los Lara y la monarquía fue endémico y solía percibirse la fuerza de la familia como un contrapeso a las aspiraciones de la corona. Tal papel por parte de la nobleza fue todavía más significativo si tenemos en cuenta la ausencia de una institución representativa realmente poderosa. Las Cortes del siglo XIII parecen todavía bastante débiles. Aunque tuvieran un grado de control en cuanto de los impuestos y fueran a menudo un foro en el cual había lugar para expresar el descontento aristocrático, no formaban todavía una institución acostumbrada a actuar contra los intereses de la monarquía. Existen, no obstante, algunòs indicios de que en la primera mitad del siglo XIV se reconoció al señor de Lara como representante de la nobleza entera. Tanto Juan Núñez II como su sobrino Juan Núñez III fueron las figuras claves de oposición en las Cortes en este período, y cierta

56 Gran Crónica de Alfonso XI, ed. Catalán, Diego: Madrid, 1977, p. 1:295.

57 "Crónica del rey don Alfonso el onceno», Crónicas de los reyes de Castilla, ed. Rosell, Cayetano: Biblioteca de Autores Españoles LXVI, Madrid, 1875, p. 179.

58 MARTíneZ, Purificación: «El contraste ideológico en la representación del reinado de Alfonso XI en la Crónica y la Gran Crónica de Alfonso XI» (Tesis doctoral, S.U.N.Y. Stony Brook, 1996), pp. 191-206.

Hispania, LXI/3, núm. 209 (2001) 999-1016 
María de Lara diría, en el año 1373, que «siempre habla el señor de Lara en nombre de los nobles de Castilla» ${ }^{59}$.

La confrontación entre la corona y los Lara, cada vez más marcada, no fue fenómeno aislado sino parte de un proceso más amplio por lo cual, desde mediados del siglo XIII, la nobleza castellana empezó a defender intereses y principios que chocaban con los de la monarquía. Los nobles encontraron su ideólogo más elocuente en la persona del rebelde Don Juan Manuel (1282-1348), cuya soberbia aristocrática y fe en las calidades excepcionales de un rico bombre eran resultados naturales de los conflictos de las últimas dos generaciones. Hombre de una erudición poco habitual en su clase, fue instrumental en forjar nuevas normas culturales e intelectuales entre la élite social, pero compartió plenamente el espíritu de insubordinación que aumentaba en la aristocracia castellana. Había que aguantar todo, escribió en su Libro de los Estados, excepto el deshonor; y en contraste con los nobles del siglo XII, su poder territorial le permitió una resistencia prolongada ${ }^{60}$. En enero de 1329 , mientras ponía los retoques finales a su Libro, contrajo matrimonio con Blanca, una de las cinco hermanas de Juan Núñez III de Lara. Poco más de un año antes, se había visto despojado de sus cargos reales, y una alianza rebelde se fue perfilando rápidamente en torno de Don Juan y su cuñado. Según la crónica, arregló un nuevo matrimonio entre Juan Núñez y la joven María de Haro (hija de Juan el Tuerto, ejecutado por Alfonso XI), alegando que ésta fue heredera legítima del señorío de Vizcaya, posiblemente el señorío más lucrativo del reino, e inició la lucha militar para su recobro ${ }^{61}$.

Aunque muy probablemente merezca el papel de conspirador con que se le juzga en la crónica, los orígenes de la guerra sobre Vizcaya en la década de los 1330 eran mucho más profundos. Ya durante tres generaciones, la familia había intentado establecerse en amplios territorios fronterizos. Hasta este momento, el foco de estos intentos había sido la frontera aragonesa -Albarracín, Molina- pero la estrategia patrimonial fue contínua.

Asimismo, la política de Alfonso XI sobre Vizcaya era un aspecto más de una afirmación general de autoridad real. Tal y como Hilda Grassotti ha demostrado, esta estrategia envolvía primeramente la defensa del patrimonio real al limitar en número de concesiones en merum imperium o señorío jurisdiccional completo, que ya había empezado a proliferar en la primera parte del siglo. De cualquier manera, la reafirmación del poder real no sólo había afectado directamente los intereses de los Lara en la acumulación de patrimonio sino que, de

\footnotetext{
59 «Crónica del rey don Enrique II», Crónicas de los reyes de Castilla, ed. Rosell, Cayetano: Biblioteca de Autores Españoles LXVIII, Madrid, 1875, p. 20; O'CALLAGHAN, Joseph: The Cortes of Castile-León, 1188-1350, Philadelphia, 1989, pp. 70-71.

60 Don Juan Manuel, Libro de los Estados, ed. R.B. Tate and I.R. Macpherson (Oxford, 1974), pp. xxxviii, 132.

61 Crónica del rey don Alfonso el onceno, 223; Gran Crónica de Alfonso XI, 1:470, 495.
} 
modo más general, provocó el amplio desafecto de los nobles. Para muchos señores esta era una era de caída en los ingresos. La inflación en los precios de la comida se elevaba consistentemente en los primeros años del siglo XIV, y varias crisis agrarias (por ejemplo en 1331-33 y 1343-46) vinieron a agravar la situación. Las repetidas devaluaciones de la moneda $(1330,1343)$ llevaron al acentuamiento y contribuyeron a la creación de un círculo vicioso de depresión económica. La inflación también había acentuado el desasosiego político y elevado sensibilidades territoriales a finales del siglo XIII y principios del XIV. Es posible que la tensión económica de 1331-33 estuviera asociada, una vez más, al escalamiento de la crisis política.

En la última década del reinado de Alfonso XI una apariencia de armonía se reestableció entre la familia Lara y la corona. Una fase de éxitos e Andalucía había transformado la corte en un centro de atracción política virtualmente irresistible. Juan Núñez mantuvo sus puestos de alférez y mayordomo hasta la muerte del rey, y parecía ser considerado ahora como el mayor exponente de servicio a la corona. Sin embargo, esta armonía era ilusoria. La tirantez entre la nobleza y la monarquía se vería fuertemente acentuada tras la sucesión de un rey tan hostil como lo fue Pedro I el Cruel. La crónica del reinado de Pedro, escrita bajo una dinastía usurpadora, la de los Trastámara, oscurece la realidad de que su política no se distinguió de manera radical de la de su padre, Alfonso $\mathrm{XI}^{62}$. Ambos intentaron centralizar el gobierno de Castilla y minar lo que en su juicio fue la influencia inmoderada de la nobleza, confiando en su lugar en letrados de origen más humilde. Agravó las tensiones la antipatía personal de Pedro hacia los Lara que resultó de la proximidad de éstos con Leonor de Guzmán. Pero por debajo de estos resentimientos personales y la crueldad legendaria del rey existía un conflicto de intereses mucho más trascendente, conflicto que, siendo más grande que los Lara, también les sobrevivió. Hay tres rasgos esenciales en la relación entre la corona y la nobleza después de la subida de los Trastámara, y cada uno de ellos fue experimentado con anterioridad por los Lara. Se trata de los intentos de la monarquía de desarrollar nuevos mecanismos administrativos para superar a la alta nobleza, la evolución de una aristocracia con un inmenso poder patrimonial y jurisdiccional y, finalmente, la guerra civil. Luís Suárez Fernández escribió que fueron estos conflictos civiles, interminables y laberínticos, la constante a lo largo de la época de los Trastámara. Los grandes juristas de la época consideraban que la monarquía era una forma superior de gobierno y, cada vez más, la opinión popular vio en el aumento del poder real el único remedio posible para detener el desorden de la guerra civil. Sin embargo, según Suárez, no deberíamos asumir tan fácilmente que el monarca posea el monopolio de la bondad, ni la nobleza el monopolio

62 EsTow, Clara: Pedro the Cruel of Castile, 1350-69, Leiden, 1995, pp. xiii-xxvi. 
de la perversidad ${ }^{63}$. Esta consideración es particularmente importante para evitar juicios morales y estereotipos a la hora de una interpretación de los Lara en sus confrontaciones con la corona. Adentrados en el siglo XV fue la aristocracia, y no la monarquía, la fuerza dominante de la sociedad castellana, situación que se prolonga a la España de los Habsburgos. Como escribe Perry Anderson, no había otro estado absolutista en la Europa del oeste tan noble en su carácter. Solamente en España, añade, fracasó el intento del absolutismo de aplastar la resistencia corporativa de la nobleza ${ }^{64}$. Las reformas de los Reyes Católicos tendrían lugar dentro de una estructura social y mental fundamentalmente aristocrática. Esta estructura no impidió la influencia de la voluntad, ni la responsabilidad moral, sino que les encauzó, creando una sociedad en la que, más que en ningún otro país de la Europa occidental, eran preponderantes el concepto, la cultura y la autoridad de la nobleza.

63 SUÁREZ FERNÁNDEZ, Luís: Nobleza y monarquía: puntos de vista sobre la bistoria política castellana del siglo XV, Valladolid, 1975, pp. 10-13, 116-117.

64 ANDERSON, Perry: The Lineages of the Absolutist State, London, 1984, pp. 60-61, 68.

Hispania, LXI/3, núm. 209 (2001) 999-1016 